\title{
Discussion on the Construction and Practice of the Professional Practice Teaching System of Education in Colleges and Universities
}

\author{
Zhang Juan
}

\author{
Yunnan University of Economics and Management, Kunming, Yunnan 650106
}

\author{
Keywords: University sports major education; Practical teaching; Build; practice
}

\begin{abstract}
The education development level in China's universities is gradually improving. However, the theory and practice of Chinese PE are not well combined. Due to the social and historical problems left over by China, traditional sports are still widely adopted in China's physical education, lacking teaching content that follows The Times closely. Moreover, there is no environment suitable for PE development in China. As a result, our practical contents cannot be fully covered. The professional quality and teaching facilities of teachers need be improved urgently. This series of problems seriously affected the sports education practice level. In view of this phenomenon, China's college PE specialty should formulate relatively complete and comprehensive teaching content, create a more satisfying practice environment for students, and provide the equipment needed for practice. All the teaching staff should also strengthen the training of teachers and actively improve the assessment system. The educators should perfect the integrated system through various ways, and provide guarantee for the high-efficient sports major to cultivate high-level and high-quality talents.
\end{abstract}

\section{Introduction}

The Sports majors in colleges and universities can help the country cultivate sports talents. It can also help Chinese people improve their comprehensive sports quality [1]. The development of sports education in colleges and universities can improve students' physical fitness and also promote the dissemination of sports theories and skills. Practical teaching is an indispensable part in physical education. Through the physical practice, students can deepen their understanding of the theory and truly apply the theory in practice. They can also improve their quality and athletic skills. Practical teaching can provide excellent reserve talents for the construction of China's sports undertakings and strengthen the practicability of sports education. Therefore, sports practice education is an important part of university education..

\section{Existing Problems in College Sports Practice}

\subsection{The teaching methods and contents are outdated}

Nowadays, students majoring in physical education in colleges and universities in China have good theoretical knowledge but do not have enough corresponding practice to practice, understand and master. Due to problems left over by history in China, there is not enough attention to physical education courses, no strict and standard teaching plans and courses, no rigorous teaching objectives, and the lack of professional management, resulting in poor education results. In the process of teaching, the proportion of theoretical teaching is large, and the arrangement of practical courses is less, which makes it impossible for students to practice effectively. Secondly, nowadays, high-efficiency PE teaching has a strong purpose, which is in conflict with the results of China's PE teaching planning. The main outlet of PE talents in China's universities is excellent PE teachers in primary and middle schools, while the main purpose of current college teaching is to meet the employment demand of students after graduation, so the practical content is also inconsistent with the goal. The traditional form of education in China is spoon-fed education, which lacks the cultivation of students' autonomy, and the teaching method is not innovative, which makes the students' implementation psychology low and the active learning poor, thus reducing the strength of practice [2]. 


\subsection{Lack of teaching equipment and professional platform}

In the current teaching practice process, most university budgets cannot meet the needs of teaching equipment, so they cannot perfect the teaching place and the professional implementation, thus affecting the learning effect of students. At the same time, due to the limited conditions, the school is unable to organize large-scale practice activities. The general practice is only limited to the school and cannot meet the necessary connection between practice education and social needs, which is not conducive to the development needs of students after graduation and has an impact on students' employment [3].

\subsection{Lack of professional education talents}

Current our country environment and under the influence of traditional concepts, for teachers and school sports curriculum value degree is not enough, many teachers lack of professional level, the need of practice courses of high quality teachers combining theory to elaborate, and take into consideration of the actual conditions and environmental factors, as school scheduling problem and appraisal and so on many factors, many teachers can't complete with good quality for the preparation work of practice teaching, the students practice the effect to sell at a discount greatly, not only affect teachers' education level, also affects the students' practice ability. Secondly, many teachers come from schools without specific practice or experience accumulation, so they cannot truly form a systematic approach path to improve students' practical ability, and their guiding role is also lack of professional level, which is not conducive to students' long-term development [4].

\subsection{The current practical level assessment system is not perfect}

China adopts the traditional education assessment method, and the final score assessment system is also used in the physical education assessment. In order to get the scores, some students take the exam by improper means, and get through the assessment by using the loopholes in the current system, either by replacing the exam or by bribing the teacher. Secondly, the examiners have strong subjectivity, which cannot guarantee the complete fairness and fairness of the appraisal. Meanwhile, due to the numerous and complex appraisal items, which involve many standards, some teachers cannot accurately apply the standards, resulting in the authenticity of the appraisal results being questioned. At the same time, due to the time and course limitations, it brings new challenges to the assessment work [5].

\section{Specific Implementation Contents of College Sports Practice}

\subsection{The basic content of college sports practice}

In making the practical contents of colleges and universities, the situation of schools and regional development should be considered comprehensively. Although some colleges and universities have insufficient facilities, they can provide a good talent reserve function for local economic development and sports culture construction. When making practice plans, it is necessary to coordinate various information, pay attention to the status of social demands, examine the conditions of talent demands of different employers, and formulate practical teaching plans according to specific demands, laying a foundation for cultivating students' good employment conditions and market competitiveness after graduation [6]. In the teaching content to develop at the same time should be according to the targeted response to students' actual situation, according to the students of different age and grade level, set different practice content, practice content system is mainly divided into inside and outside class, practices centralized and decentralized centralized type, fully meet the practical requirements and conditions of the school, promote the integration of internal and external practice class, in order to promote the practice result optimization, practice quality of ascension.

\subsection{Practical contents in class}

In the process of classroom teaching, students are guided to master knowledge through various ways to promote the cultivation of students' practical ability, language ability, basic teaching ability and other abilities. Specific courses include physiology, anatomy, classroom lecture, taking turns to lead the team and other comprehensive contents. Explain to the students demonstrate basic password and formation, through gymnastics movements, guide students to practice gymnastics autonomous let students complete 
the preparation process, the students on hand process and guide the student to study the related content, the students on the playground descriptive knowledge, skills, and all kinds of ball games, track and field referee knowledge deepen students for sports knowledge and application, and cultivate the students' initiative [7].

\subsection{Extracurricular practices}

Extracurricular practice includes various contents, which can fully mobilize students' enthusiasm and enthusiasm. First, organize students for middle and primary school sports facilities, construction, course, activities, encouraging students to participate in actively, at the same time let the students understand the content of the involved in the local primary and secondary school physical education, based on the related teaching concept, methods and process of learning, to deepen student for master degree theory, at the same time can guide students to learn from the outstanding talents of physical education, cultivating students' long-term development goals, future planning to provide the reference for the students, further improve the effect of students' practical education. Second, the school can encourage students to take an active part in many external sports competitions and conduct social practice interviews and surveys. To participate in various types of sports competitions, improve students' requirements for themselves, and at the same time expand students' vision, strengthen students' ability to cooperate and the cultivation of various excellent wills. Let students have a deeper understanding of the society, more clearly understand the needs of the society for talents, let students think deeply, and increase students' judgment and self-determination ability.

\subsection{Focus on practical content}

Using a variety of ways to cultivate students' comprehensive ability, through ball sports training of the students' sports skills, such as in order to facilitate to the education career development in the future, the education practice ability of students can be through the professional training skills training courses, lets the student in the curriculum combines the related theory and practice, through teaching explanation, micro courses in a variety of ways, such as let students not only to understand knowledge completely, and can skillfully use, through games and contests with knowledge related to cultivate students' learning interest and deepen the knowledge to master degree. Let students visit the process of making and implementing the teaching plan to prepare students' teaching ability. The university organizes large-scale activities to encourage students to participate actively, such as various calligraphy competitions, various cultural and recreational activities to improve students' comprehensive quality, various sports competitions to improve students' professional quality, and to promote students to consolidate themselves while promoting comprehensive development, in line with the concept of quality education. At the end of the course should organize internships main is to organize students to participate in local primary and secondary school curriculum teaching assistant or visit help, through the concrete teaching activity, study the specific teaching environment and conditions, through the specific implementation of lesson preparation, teaching, understand the details of primary and secondary schools teaching in-depth research course. Cultivate students' literacy through organizing relevant lectures and BBS, popularize education concept. Let students prepare graduation thesis and publish scientific research results. Cultivate students' ability to observe, think and solve problems through independent innovation and entrepreneurship, graduation thesis design and social investigation.

\section{Practical Methods of College Sports Education}

\subsection{Improve the teaching platform to promote practice}

In practice, perfect equipment and excellent platform are indispensable. In high efficiency, relevant funds should be set up to budget for the excellent platform of infrastructure equipment construction. Meanwhile, time should be allocated appropriately according to the curriculum arrangement of students of different grades, so that every student can have sufficient opportunities to put into practice. In addition, colleges and universities should make good use of their own resource advantages to strengthen contacts with regional organizations in order to carry out relevant activities and organize students to complete 
internships. Increase the connection with the institutions of primary and secondary schools, organize students to observe and investigate, improve students' practical ability and broaden their vision, understand the social needs, enable students to develop long-term development goals, and facilitate the learning process to be more targeted and targeted. Only by satisfying students' practical needs through various platforms can the education method and education form truly meet the requirements in the current environment [8].

\subsection{Improve the professional quality of teachers}

Lack of current our country sports teachers' professional level literacy, relevant personnel for physical education curriculum value degree is not enough, lack of education personnel's professional skill levels, the requirement of high quality in the process of education practice course requires teachers combining theory to elaborate, and take into consideration of the actual conditions and environmental factors, many teachers cannot complete the request, because the school scheduling problem and appraisal and so on many factors, teachers completed preparations for the practice teaching is a problem with good quality, makes the student practice effect. Therefore has been outstanding professional quality of teachers is the key, in the process of teachers training, on the one hand need teachers have strict requirements, continuously improve their professional level, positive continuously improve self-learning, on the other hand to school teachers need to be good experience exchange, improve teachers' education concept, by relevant lectures, meeting to share experience and learn from each other to realize their own promotion and mutual supervision, can also organize teachers to participate in the activities of practice and visit, excellent teacher evaluation activities, through corresponding rewards and punishment measures mentioned the enthusiasm of the teachers at the same time, to stimulate teachers promote business capabilities.

\subsection{Improve the assessment system}

When carrying out practical teaching assessment, due to numerous factors affecting the assessment process, the assessment staff is highly subjective, and the fairness and fairness are affected. Therefore, it is necessary to strengthen the flexibility of assessment. Evaluation and the specific content of the time and place can adjust and control, make the students can be free to choose, and reference in the process of teaching students a variety of performance, whether on time, actively cooperate with the teacher in class activities organization, improve the students the importance of daily learning process, to avoid cramming happens, prevent because at ordinary times is not involved in learning to the test when hoping for a score by unfair means. Some assessment items do not have clear standards. At this time, the assessment can be carried out under the quantitative basic conditions through qualitative assessment, reducing the subjective component of the assessor, so as to strengthen the fairness and fairness of the assessment results and make the final score more realistic and objective. We should give full positive encouragement and support to the students' progress so as to improve their enthusiasm for learning.

\section{Conclusion}

China should pay attention to the development of education while developing economy. College sports education is one of the important contents. In formulating the sports education plan, we should base on the basic national policies and principles of our country and aim to develop students' comprehensive quality and ability comprehensively. At the same time, we should also consider the specific market needs of different regions and make corresponding plans to meet social needs. The education program should be consistent with the development of students. This paper mainly analyzes the existing problems in the practice of physical education major in colleges and universities in China, and puts forward relevant reference Suggestions, in order to further improve the education level in China and make contributions to the construction of science and technology culture in China. 


\section{References}

[1] Shi Ruoyan. Exploration of professional practice teaching system of education major in university sports [J]. Journal of Xuchang College, 2011, (2):149-151.

[2] Chen Yajing. Investigation and research on professional practice teaching of education major in colleges and universities [D]. Henan University Press, 2016.

[3] Chen Yajing. Study on optimization of professional practice teaching system of education in colleges and universities [J]. Contemporary sports science and technology, 2015, (16):49-51.

[4] Liu Shen. Investigation and analysis on the status quo of the cultivation of teaching practice ability of students majoring in PE in local universities in Yunnan province [J]. Discovery (education edition), 2016, (5):90-91.

[5] Ding Xiaofan. Reform and practice of sports dance teaching in Hunan university sports education [J]. Study on course education, 2016, (23):205-205.

[6] Zheng Zhidong. Practical research on the teaching reform of track and field course in education major of university sports [J]. Neijiang Keji, 2012, (2):56-56, 31.

[7] Zhang Mingwei. Research on the curriculum teaching model of practical teaching ability of students majoring in physical education in education major in universities [J]. Journal of Dalian University, 2015, (3):131-134.

[8] Nan Qiuhong. Research on the construction of practical teaching system of PE education major (Journalism direction) in private universities [J]. Sport, 2013, (19):96-97. 